\title{
DIAGNOSTICUL PRENATAL AL TETRALOGIEI FALLOT ŞI IMPLICAȚIILE POSTNATALE
}

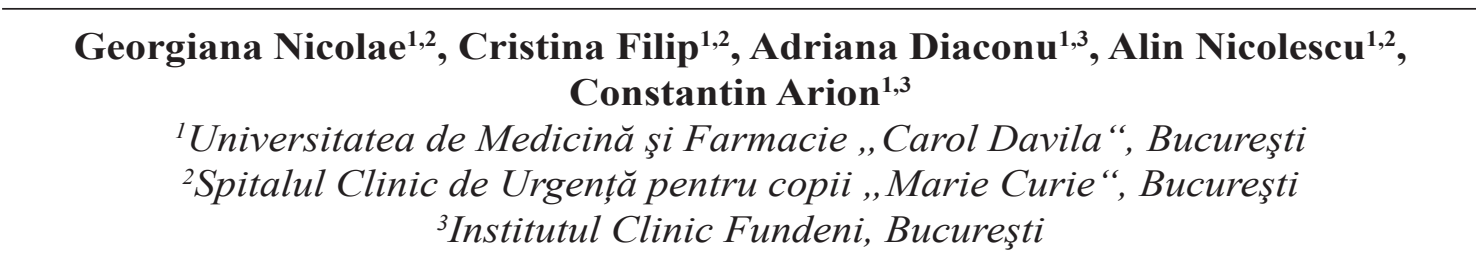

\begin{abstract}
REZUMAT
În ultimii ani, diagnosticul prenatal al malformațiilor de cord a cunoscut o dezvoltare importantă. Supravietuirea globală a pacienților cu malformații congenitale de cord s-a îmbunătățit în ultima decadă, datorită diversificării atât a metodelor de diagnostic, cât şi a celor de chirurgie cardiovasculară pe această arie de interes.

Ca urmare a creșterii semnificative a supravietuirii pe termen lung, în prezent, în majoritatea țărilor dezvoltate există departamente dedicate monitorizării adulților cu malformații congenitale de cord, datorită particularităților şi nevoilor speciale ale acestui tip de pacienți, în comparație cu patologia cardiacă dobândită a adultului.

Articolul de față îşi propune o trecere în revistă a datelor existente până la acest moment legate de diagnosticul prenatal şi impactul acestuia asupra evoluției postnatale în ceea ce priveşte cea mai frecventă malformație congenitală cianogenă, şi anume Tetralogia Fallot. În cele ce urmează, reiterăm importanța cunoaşterii cu exactitate a patologiei fetale prenatale pentru stabilirea din timp a conduitei medicale postnatale pentru copiii cu acest tip de malformație.
\end{abstract}

Cuvinte cheie: malformație congenitală de cord, Tetralogie Fallot, diagnostic prenatal

Incidența bolilor congenitale de cord, în Romania, este de 7,5/1.000 de nou-născuți vii (1).

Majoritatea anomaliilor de cord se pot vedea din săptămâna a 12-a de sarcină la o examinare ecografică realizată de un medic experimentat cu un aparat performant (ex: Tetralogia Fallot, hipoplazia de ventricul stâng sau drept, defectul septal ventricular). La vârsta de 16-18 săptămâni de sarcină se vizualizează: defectul septal atrial, stenozele valvulare, transpozitiia de mari vase (2).

Tetralogia Fallot (TOF) este cea mai frecventă malformație de cord cianogenă, cu o incidență de 32,6 la 100.000 de nou-născuți vii. Acest tip de malformație beneficiază de corecție chirurgicală completă, prognosticul pe termen lung şi scurt fiind influenţat de particularităţi anatomice ce pot fi vizualizate în perioada fetală, de tehnica chirurgicală şi prezența anomaliilor asociate (3).

Descrierea originală a TOF a inclus următoarele patru anomalii: defect septal ventricular larg (DSV), obstrucție în tractul de ejecție al ventriculului drept (RVOT), hipertrofia ventriculului drept
(HVD) şi dextropoziția aortei. În realitate, doar două anomalii sunt necesare, un DSV suficient de mare pentru egalizarea presiunilor între ventriculi şi obstrucția RVOT (4).

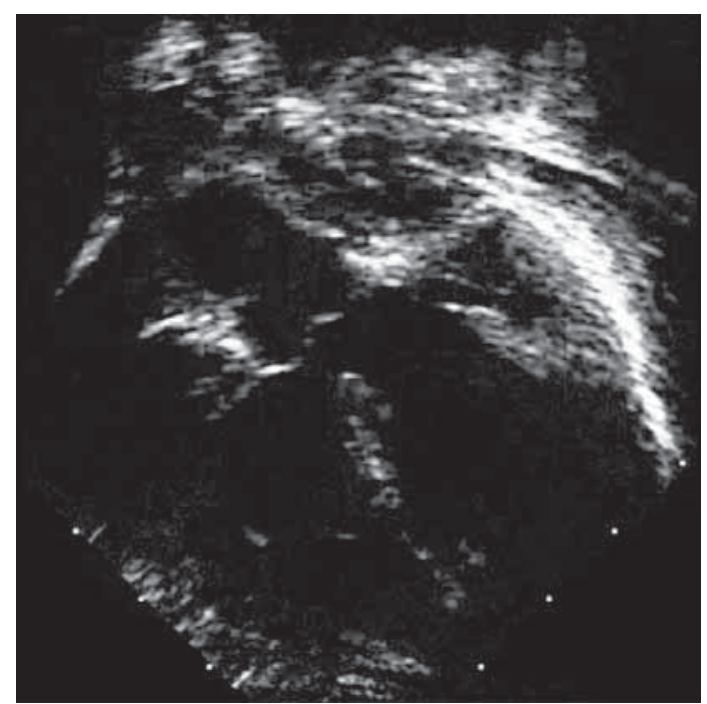

FIGURA 1. Secțiune modificată apical 4-camere evidențiind malalinierea aortei şi defect septal ventricular 
Obstrucția RVOT este întâlnită cel mai frecvent sub forma de stenoză infundibulară $(45 \%)$. Obstrucția este rareori la nivelul valvei pulmonare $(10 \%)$. O combinatie a celor două poate să apară, de asemenea, (30\%) (Fig. 2).

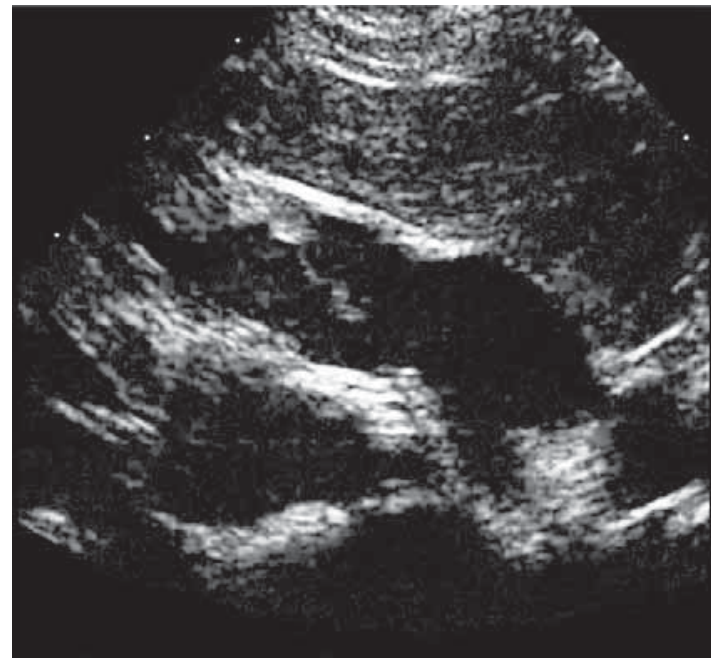

FIGURA 2. Secțiune parasternală ax lung înaltă, angulată către stânga pentru vizualizarea hipertrofiei infundibulare subpulmonare şi hipoplazia uşoară a inelului valvei pulmonare

Valva pulmonară este atretică în forma cea mai severă a anomaliei (15\%) (4) (Fig. 3).

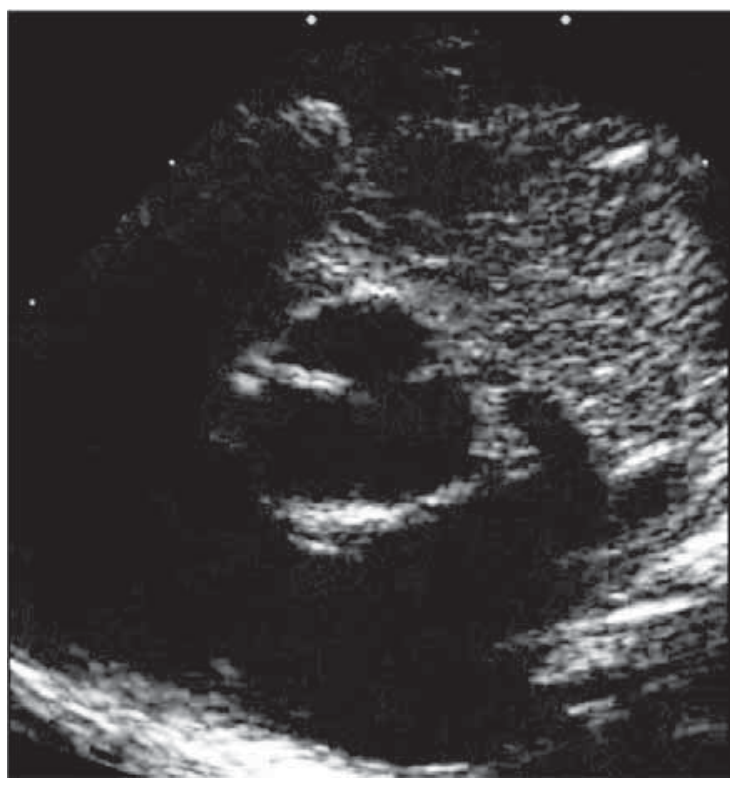

FIGURA 3. Secțiune parasternal ax-scurt evidențiind atrezia valvulară pulmonară

Inelul valvei pulmonare şi principalele ramuri pulmonare sunt variabil hipoplazice la majoritatea pacienților. Ramurile arterei pulmonare (AP) sunt de obicei mici, cu toate că hipoplazia severă este mai puțin frecventă. Stenoza la origine a ramurilor AP, în special AP stânga, este comună. Ocazional, există artere colaterale sistemico-pulmonare care asigură fluxul pulmonar, mai ales în cazurile severe de TOF. În $25 \%$ din cazuri, este prezent arc aortic drept, uneori apărând simptome de inel vascular. La aproximativ 5\% dintre pacienții cu TOF, sunt prezente arterele coronare anormale. Cea mai comună anomalie este prezența unei ramuri descendente rezultată din artera coronară dreaptă, ramură care trece peste RVOT şi care contraindică o incizie chirurgicală în regiune. Canalul atrio-ventricular comun complet apare la aproximativ $2 \%$ dintre pacienții cu TOF, mult mai frecvent în rândul pacienților cu sindrom Down. La aceşti pacienți, DSV are o componentă inlet largă, asociată componentei outlet mare din cadrul canalului atrio-ventricular comun (5).

Poon şi colaboratorii au raportat experiența lor privind diagnosticul fetal al TOF la vârsta gestațională medie de 20,6 săptămâni.

Anomaliile extracardiace s-au asociat la aproximativ 30\% dintre copiii afectați iar incidența poate creşte până la 50-60\% în cazurile de TOF diagnosticată fetal.

Evaluarea şi consilierea prenatală corectă pentru TOF implică metode de screening avansate pentru anomaliile extracardiace, cum ar fi cele cromozomiale.

Diagnosticul de TOF poate să nu fie evident la evaluarea ecocardiografică din secțiunea apical 4-camere. Vizualizarea tractului de ejectie al VS din secțiunea apical 5-camere va evidenția malalinierea aortei iar interogarea Doppler color vizualizează direcția fluxului sanguin dinspre ambii ventriculi către aortă. Secțiunea ax scurt la baza marilor vase demonstrează devierea septului conal, malalinierea DSV şi stenoză subpulmonară.

Secțiunea 3-vase evidențiază discrepanța dintre dimensiunile vaselor, cu aorta mult mai largă decât artera pulmonară, poziția arcului aortic şi anomaliile acestuia, inelul vascular fiind mai uşor de vizualizat în viața fetală, datorită transmiterii mai bune a ultrasunetelor în contextul plămânilor neexpansionați. În cazul stenozei pulmonare severe sau atreziei de valva pulmonară, fluxul prin canalul arterial va fi retrograd. Monitorizarea ecocardiografică prenatală este recomandată pentru aprecierea progresiei stenozei pulmonare şi a hipoplaziei progresive de arteră pulmonară (6).

Feții cu Tetralogie Fallot pot prezenta, la examinarea ecografică prenatală, doar defect septal ventricular şi malalinierea aortei (Fig. 4).

Stenoza de arteră pulmonară nu e prezentă întotdeauna la evaluarea ecografică inițială, dar această constatare se poate dezvolta sau agrava în timpul sarcinii. De asemenea, un inel aortic normal nu ex- 
clude Tetralogia Fallot. Supraviețuirea nou-născuților este favorabilă în absența altor anomalii structurale sau cromozomiale majore (7).

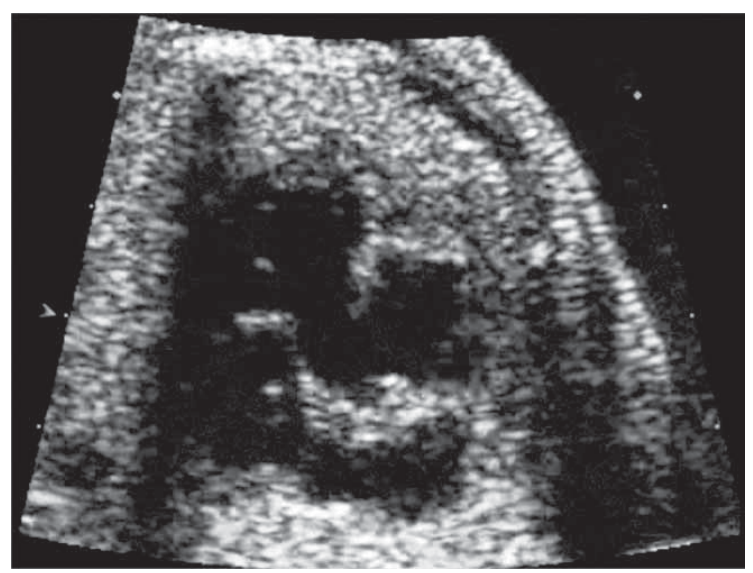

FIGURA 4. Imagine de ecocardiografie fetală, imagine de ax lung al VS cu vizualizarea DSV şi malalinierii aortice

Într-un studiu retrospectiv efectuat în California, pe o perioadă de 12 ani (1985-1997) privind anomaliile conotruncale (DORV, TOF, malpoziţia arterelor mari, transpoziția de vase mari, atrezie pulmonară, DSV, trunchi arterial comun), au fost incluse 2.470 de ecocardiografii prenatale dintre care s-au confirmat 61 de feți cu anomalii conotruncale. Vârsta medie la diagnostic a fost de 24,5 săptămâni de gestație şi concordanța între diagnosticul prenatal şi postnatal a fost de $77 \%$. S-a constatat că dintre anomaliile conotruncale, Tetralogia Fallot a avut un prognostic mai bun, cu excepția formei cu valvă pulmonară absentă. Acest studiu demonstrează că anomaliile conotruncale puteau fi diagnosticate prin ecocardiografie prenatală cu un grad relativ ridicat de precizie, chiar şi în urmă cu 10 ani. Prognosticul feților cu anomalii conotruncale era considerat rezervat cu excepția cazurilor de Tetralogie Fallot, la care supraviețuirea neonatală a fost de $75 \%$ (8).

Un review sistematic al 36 de articole din Medline şi Embase, publicat în 2016, privind evoluția postnatală a TOF, asocierea cu sindroame genetice şi concordanţa între datele ecografice prenatale şi postnatale a arătat că rata de supraviețuire a pacienților diagnosticați prenatal cu atrezie de VP sau absența valvei pulmonare este semnificativ mai scăzută față de TOF cu stenoză pulmonară la sfarşitul perioadei neonatale. Anomaliile genetice şi malformațiile asociate au fost mai frecvente în cazul TOF cu atrezie pulmonară sau absența valvei pulmonare față de TOF cu stenoză pulmonară.

În baza de date a Mendelian Inheritance in Man (OMIM) sunt înregistrate 32 de cazuri de sindroame care includ TOF ca trăsătură caracteristică.
Forma de TOF cu atrezia valvei pulmonare (pentru care în prezent cea mai acceptată terminologie este cea de „Atrezie de valvă pulmonară cu $\mathrm{DSV}^{\text {“) }}$ ) este inclusă în cadrul MCC cianogene ducto-dependente, diagnosticul fetal corect impunând inițierea tratamentului cu Prostaglandină imediat după naştere. $11,7 \%$ dintre aceşti feți au un sindrom genetic, $8,3 \%$ au anomalii cromozomiale, iar $6,7 \%$ asociază şi malformații ale unui alt organ. Deci, doar 73,3\% dintre aceşti copii nu au alte anomalii asociate recognoscibile. Cel mai frecvent sindrom genetic asociat cu acest tip de TOF (8-23\% din pacienți) este sindromul Di George/sindromul velocardiofacial (deleție 22q11.2). De asemenea, 10\% din pacienții cu deleția 22q11.2 au TOF cu atrezie de VP (aceasta formă extremă de TOF fiind aparent mai frecventă în cadrul sindromului decât alte forme de TOF). De asemenea, feții cu TOF şi valvă pulmonară atretică au mai frecvent anomalii cardiace asociate decât feții cu forme comune de TOF; astfel, asociază mai frecvent arc aortic drept, arteră subclavie cu origine aberantă, colaterale aorto-pulmonare.

TOF cu absența valvei pulmonare - reprezintă 3-6\% din totalul pacienților cu TOF; VP este absentă sau este prezent doar un rudiment al acesteia. Această variantă se asociază cu dilatare anevrismală seminficativă a trunchiului AP şi ramurilor care poate duce la compresia căilor aeriene cu insuficiență respiratorie severă de la naştere. De obicei, aceşti feți asociază şi un grad de obstacol în RVOT. O caracteristică importantă a acestei forme de Tetralogie Fallot este absenţa aproape întotdeauna a ductului arterial. 50\% dintre aceşti pacienți au arc aortic drept (9).

Diagnosticul ecocardiografic prenatal al MCC a cunoscut o dezvoltare importantă în ultimii ani. Dacă în anul 1997 concordanța între diagnosticul prenatal şi postnatal în cele mai frecvente tipuri de malformații era de $77 \%$, acum aceasta a crescut la peste $90 \%$.

Tetralogia Fallot prezintă un spectru larg de forme clinice, de la cele mai puțin severe care nu reprezintă o urgență neonatală până la cele foarte severe. Particularităţile fiecarei forme de TOF pot fi studiate în detaliu acum printr-o evaluare ecografică amănunțită (10).

Un diagnostic fetal corect al unei forme severe de TOF (cu atrezie/pseudoatrezie VP sau forma cu ramuri pulmonare sever hipoplazice) impune naşterea într-o maternitate cu posibilităţi maximale de terapie intensivă şi cu acces facil şi direct la un serviciu de cardiologie pediatrică şi chirurgie cardiovasculară pediatrică. De asemenea, neonatologul 
va iniția terapia cu prostaglandină i.v. pentru menținerea deschisă a canalului arterial până la momentul corecției chirurgicale (paleative într-o prima etapă) care este necesar a se realiza în perioada neonatală.

În cazul diagnosticării fetale a TOF cu absența VP, neonatologul va fi avizat, deoarece în cazul nou născuților care prezintă insuficiență respiratorie severă de la naştere (prin compresia căilor aeriene de către dilatația anevrismală a trunchiului AP şi ramurilor sale), copilul necesită protezare respiratorie imediată şi ventilație cu presiune pozitivă pentru menținerea deschisă a căilor aeriene. Copiii născuți cu acest tablou clinic vor necesita intervenție chirurgicală în perioada neonatală, dar aceasta implică un risc operator înalt şi rezultate postoperatorii în multe cazuri nesatisfăcătoare.

\section{CONCLUZII}

Diagnosticul fetal corect al unui făt cu TOF impune mare atenție în identificarea unor anomalii cardiace şi extracardiace asociate, precum şi investigații genetice pentru depistarea unor anomalii cromozomiale. Astfel, consilierea părinților poate fi făcută în mod realist, prezentându-se întreg contextul clinic şi genetic al copilului, posibilitățile de corecție chirurgicală şi aprecierea privind prognosticul postnatal. Este important de subliniat părinților că afecțiunea cardiacă este una care beneficiază de corecție totală, având prognostic favorabil pe termen lung în cazul în care afecțiunea este izolată. Prognosticul nefavorabil pe termen lung este legat în principal de prezența sindroamelor genetice şi a altor malformații asociate.

Este de subliniat, de asemenea, importanța evaluării în dinamică a fătului după momentul diagnosticului inițial, având în vedere posibilitatea agravării gradului de obstacol în RVOT precum şi a hipoplaziei de inel VP, trunchi AP şi ramuri AP astfel încât în apropierea naşterii severitatea bolii să fie apreciată cât mai corect. 